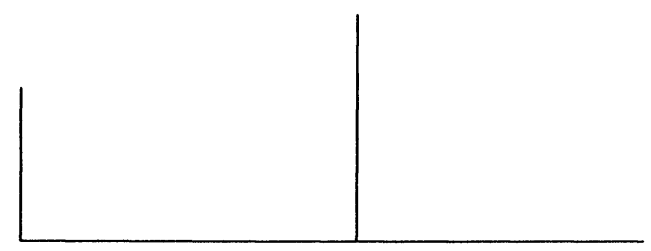

Rev. Latinoam. Psicopat. Fund., VIII, 2, 322-345

\title{
A crítica à Reforma Psiquiátrica, da sua implantação e de seus fundamentos: os argumentos de Valentim Gentil*
}

\author{
Entrevista a Mônica Teixeira
}

O tema Reforma Psiquiátrica, e sua implantação nos serviços de Saúde Pública, tem sido tratado por esta Revista com regularidade. A seção "Observando a Medicina" também deu atenção ao assunto quando, em dezembro de 2003, publicou a entrevista da psicanalista Mirsa Dellosi, da Secretaria da Saúde do Estado de São Paulo. Nesta edição, quem toma a palavra para falar sobre o modelo de atenção à saúde mental proposto pela Reforma é o doutor em psiquiatria Valentim Gentil, um seu apaixonado opositor. Como explicita na entrevista, o professor Valentim considera "irresponsável" a política em implementação - por deixar sem assistência os psicóticos graves; ao mesmo tempo, falha na atenção a quem sofre do que ele chama de "transtornos mentais comuns" e não resolve como dar assistência aos agudos. As experiências que estão na base da concepção da Reforma, acrescenta, foram bem-sucedidas pontualmente, em lugares cujas condições não podem ser reproduzidas. De acordo com o professor titular da Faculdade de Medicina da USP, o viés antipsiquiátrico da Reforma ignora

* Do Instituto de Psiquiatria do Hospital das Clínicas, Professor Titular da Faculdade de Medicina da USP. 


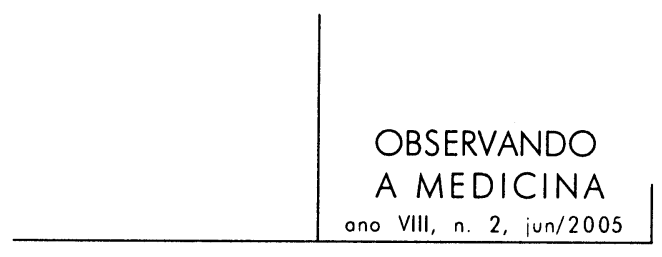

o arsenal terapêutico hoje à disposição da psiquiatria; ao fazê-lo, e ao desmontar hospitais sem substituí-los adequadamente, tem prática que ele classifica como anti-ética. Para Valentim, o sofrimento psíquico não é assunto da psiquiatria que ele advoga ser uma especialidade médica como qualquer outra. Para quem é afetado "apenas" por sofrimento psíquico - uma condição "inespecífica" -, o entrevistado recomenda a busca de uma boa relação afetiva, de uma abordagem religiosa, do consolo na filosofia; ou a psicanálise.

A entrevista foi realizada em duas sessões, em dezembro de 2004 e em março de 2005, no Instituto de Psiquiatria, em São Paulo.

Mônica Teixeira: Quais são suas restrições ao modelo de saúde mental preconizado pelo Ministério da Saúde?

Valentim Gentil: De várias ordens. O modelo ideal seria uma rede de serviços. Concordo com o princípio de que o hospital psiquiátrico não deve ser o centro, nem a porta de entrada. Não sou contra reduzir o número de leitos hospitalares especializados na medida em que eles sejam desnecessários e substituídos por equipamentos alternativos de atendimento às necessidades médicas e sociais supridas por eles. Sou contra a des-hospitalização imprevidente realizada nos últimos 15 anos. Também critico a falta de investimento em boa psiquiatria, com programas de prevenção secundária efetiva, e na prevenção primária possível, que poderiam de fato reduzir a demanda por leitos hospitalares. No modelo atual, não se prevê quase nenhuma prevenção primária em psiquiatria. Essa é uma restrição importante. Por exemplo: nunca ouvi uma palavra do Ministério da Saúde, em nenhum governo, alertando para as evidências científicas de que maconha faz mal à saúde. Ao contrário, assisto a uma atitude complacente ou mesmo simpática dos seus representantes. Além de agravar e precipitar vários quadros, a maconha fumada por meninas antes dos quinze anos aumenta em três vezes o risco de depressão; desde os anos 1980, e comprovado desde 2002 pela publicação de pelo menos cinco estudos em vários países - um deles com seguimento de 27 anos - mostrando um aumento significativo do risco para esquizofrenia entre jovens que fumam maconha uma vez por semana antes dos dezoito anos. Nunca vi o Ministério da Saúde levar em conta trabalhos científicos mostrando que infecções virais gripais, na primeira metade da gravidez, aumentam o risco de esquizofrenia; eles poderiam alertar as mulheres grávidas para evitarem ambientes onde possam se contaminar com vírus da gripe. Nunca vi uma campantha sugerindo que pessoas de temperamento instável não devem se expor a anorexígenos, estimulantes, ao abuso de álcool. Isto é prevenção primária em saúde mental, possível e justificável, mesmo que seja politicamente difícil.

M. T.: Mas isso não é pedir demais ao Ministério da Saúde? 


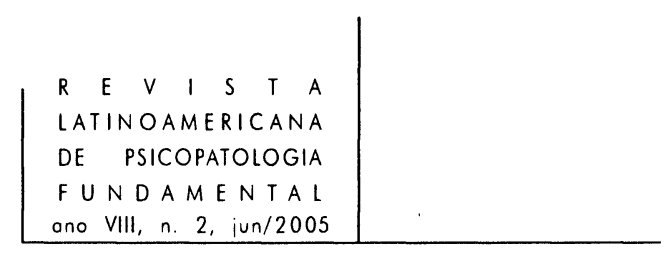

V. G.: Não. É obrigação. Em algumas áreas da saúde se faz prevenção. Mas por que o Ministério não faz mais? Porque a estrutura de saúde mental é muito pequena, ineficiente e fica perdida na questão que foi tomada como bandeira - o fechamento dos manicômios. Também não se faz prevenção secundária. Por que não? Talvez porque prevenção secundária tenha que ser feita com boa medicina, e boa clínica psiquiátrica não é prioridade nessa política, comprometida com a corrente da reabilitação psicossocial e des-medicalização da psiquiatria.

\section{T.: $O$ que o senhor chama de prevenção secundária?}

V. G.: Quando se detecta precocemente uma doença, é possível intervir de forma eficaz e impedir que ela cause mais problemas e sofrimento. Os mais favorecidos no Brasil podem ter prevenção secundária: quando detectam algum problema ligam para o médico, que indica um serviço psiquiátrico qualquer e intervém precocemente. Apesar disso, leva-se muitos anos para chegar ao diagnóstico definitivo, porque existe um grau de incompetência no sistema. De qualquer forma, cada vez que alguém começa a entrar em fase ou em surto, há intervenção precoce, a pessoa não chega a ser internada. No meu consultório, quase não interno - trabalho com gente com depressão grave, mania. Isso é verdade para

324 a maioria dos psiquiatras que atendem em clínica privada. Entretanto, só no Estado de São Paulo, mais de 10.000 Autorizações de Internação Hospitalar são feitas todos os anos, apenas para depressão bipolar e mania, demonstrando a falta de prevenção secundária efetiva. Como se poderia fazer prevenção secundária neste país, no SUS? Implementando uma rede de serviços ambulatoriais - não prontos-socorros, como preconiza o modelo - para o acompanhamento dos pacientes e suas famílias, e à qual as pessoas possam recorrer quando apresentam os primeiros sinais de recaída. Isso seria eficiente para reduzir internações.

\section{T.: Os defensores do modelo atual afirmam que os Centros de Atenção} Psicossocial deveriam prestar esse serviço.

V. G.: É só olhar os números: quantos CAPS existem? Quantas pessoas são atendidas nos CAPS? Entrei no site do Ministério da Saúde em agosto de 2004 e lá constava existirem 546 CAPS, dos quais 64 eram para álcool e drogas e 41 para crianças e adolescentes. Sobram 441 para os adultos com todos os outros quadros, especialmente as psicoses. Os dados do site mostravam também um salto no número de atendimentos nos CAPS, de $389 \mathrm{mil} \mathrm{em} \mathrm{2002,} \mathrm{para} \mathrm{3,7} \mathrm{milhões}$ em 2003. Dá para acreditar? Sem aumentar proporcionalmente o número de funcionários e o número de CAPS? Deve ter havido algum erro de aritmética. O fato é que, não apenas os hospitais, mas também a rede ambulatorial foram desmontados antes de haver uma rede alternativa. A estrutura de CAPS não visa 


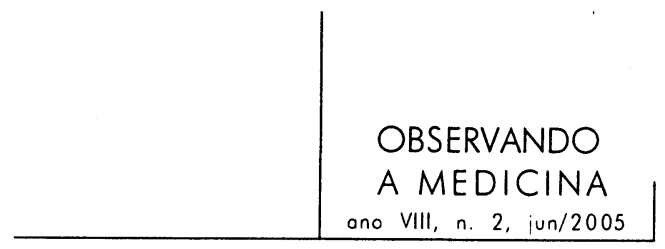

ampla prevenção secundária psiquiátrica: é basicamente voltada para o acompanhamento de um determinado grupo de pacientes com equipe multiprofissional, visando "prevenção de todos os níveis" - entre aspas. O modelo adotado atua como se psiquiatria fosse apenas a "clínica das psicoses". Trabalhar com reabilitação, hospital-dia, para dar atendimento em substituição à hospitalização é importante. Mas não é a melhor forma de fazer prevenção secundária dos principais transtornos mentais, pois a maioria dos transtornos mentais não vai parar nos CAPS - são pessoas com depressão, pânico, fobias, transtorno obsessivo-compulsivo, ou transtorno bipolar maníaco-depressivo. Esses são transtornos mentais que não precisam, não procuram e não aceitam o tipo de atendimento oferecido pelos CAPS. O modelo SUS propõe uma estrutura de Unidade Básica de Saúde (UBS) e Programa de Saúde da Família (PSF), para detectar e tratar transtornos mentais comuns. Basta ir às UBSs e aos PSFs e ver se eles têm competência psiquiátrica para fazer isto. A resposta é: não - nem aqui nem nos outros países. Quanto tempo vai levar para que essas equipes estejam capacitadas a fazer boa prevenção secundária, para os municípios montarem uma rede ambulatorial em substituição à rede estadual, se o SUS remunera muito mal uma consulta psiquiátrica? Qual é o prefeito que vai poder contratar esses serviços, a $\mathrm{R} \$ 2,54$ por consulta? O modelo todo é assim: não tem boa prevenção primária onde dá para fazer - que é pouco - e não tem boa prevenção secundária, porque CAPS e pronto-socorro não servem para isso.

M. T.: Mas nem o Estado de São Paulo tem uma rede de ambulatórios de saúde mental? Mirsa Dellosi, da Secretaria da Saúde, em entrevista dada a esta revista, em dezembro de 2003, disse que essa rede existe.

V. G.: Com exceção dos hospitais universitários e de servidores, a rede de ambulatórios estaduais está sendo fechada ou já fechou, pois o Sistema Único de Saúde manda municipalizar - mas o município não tem recursos para montar a rede alternativa para saúde mental ou mesmo ter um psiquiatra. Para alguns, os problemas psiquiátricos podem ser atendidos em cuidados primários, como se um generalista pudesse diagnosticar e tratar os transtornos mentais de crianças a idosos. Não é verdade. Talvez clínicos bem treinados possam dar conta das depressões. Quem olha os dados da OMS, recentemente publicados (J.A.M.A., junho de 2004) vê que, mesmo nos países mais desenvolvidos, de 35 a $50 \%$ dos casos mais graves de transtornos mentais comuns não recebem atendimento num período de 12 meses. Nos países menos desenvolvidos isso chega a mais de $85 \%$. No modelo brasileiro não se faz boa prevenção secundária conseqüentemente, os casos se agravam. Alguns mentores da nossa reforma propõem que o Pronto-Socorro seja uma porta de entrada. Ora, Pronto-Socorro 


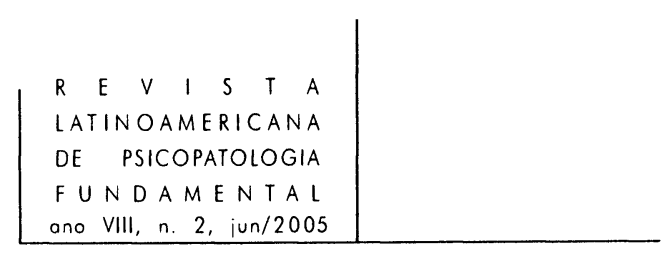

é indício de falência do sistema: só se vai ao pronto-socorro com problema psiquiátrico porque ele se agravou a tal ponto que a família não pode mais cuidar. O caso ocupará o espaço e o tempo de alguém que deveria estar atendendo um infarto, ou um acidente - que são imprevisíveis. Pronto-Socorro não é para tratar depressão - não tem cabimento. Depressão você detecta precocemente, intervém, aborta e pronto.

M. T.: Mas o que se vê no hospital público com deprimidos não pode ser descrito dessa maneira: "intervém, aborta e pronto". A clínica mostra que os deprimidos, medicados ou não, são muito renitentes...

V. G.: Se você detecta precocemente um quadro depressivo, sua chance de livrar a pessoa dessa depressão imediatamente é muito alta. A maior parte das depressões médicas - não existenciais, médicas -, principalmente aquelas conhecidas há séculos, endógenas, são depressões com começo, meio e fim. A maior parte desses quadros entra em remissão. Outra coisa é a depressão neurótica, de baixa intensidade - aí talvez a eficácia seja menor.

M. T.: Entre esses deprimidos, o senhor não reconhece um componente que não é biológico?

V. G.: Chamo de depressão não os sintomas, mas a síndrome. Se não houver um componente biológico, a síndrome não se instala. Sua causa é multifatorial, mas a vulnerabilidade biológica é fundamental. Estou falando do quadro clínico definido medicamente como depressão. Não estou falando de depressão em senso amplo.

M.T.: Mas o senhor falava do tratamento em pronto-socorros...

V. G.: Não é no Pronto-Socorro que se atende nem depressão, nem casos de transtorno bipolar agravado. É para esperar alguém entrar em mania, chegar ao Pronto-Socorro e tomar uma injeção? Não: você faz prevenção secundária eficaz. Nestes últimos 25 anos, quase nada se fez no país para montar uma rede assim. Estamos fazendo um projeto em São José do Rio Preto, financiado pela Fapesp em parceria com a Faculdade de Medicina e de Enfermagem de lá, testando prevenção secundária de transtorno bipolar, junto com as Unidades Básicas de Saúde. É um projeto de pesquisa, porque é necessário provar que aquilo é eficiente, para depois recomendar para governos - e não ir implementando procedimentos que não foram sequer testados, como é o costume no Brasil. Quando as pessoas já estão mais comprometidas, é preciso fazer prevenção terciária, que requer maior complexidade no atendimento, em geral em hospital especializado de bom nível, uma raridade em extinção no modelo. O que os 


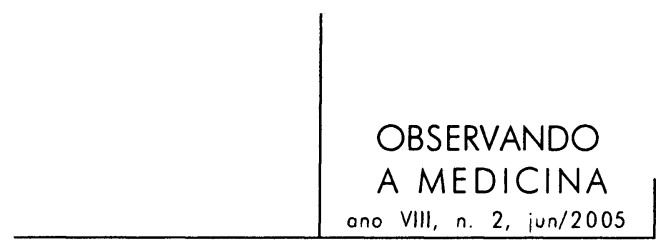

governos fizeram, nos últimos 15 anos? Montaram CAPS mal equipados, com recursos humanos pouco qualificados e baixa resolutividade. Não há no Brasil alguém que vá defender manicômios...

M. T.: Nem o senhor?

V. G.: Já escrevi muitas vezes que não defendo manicômio - para mim, mistura de asilo, com hospital, com prisão. Segundo a "Justificação" do projeto Paulo Delgado, de 1989, havia 120 mil leitos psiquiátricos no Brasil - "100 mil remunerados pelo setor público e cerca de 20 mil leitos estatais" (sic*). Em 2004, segundo a página do Ministério da Saúde, existiam 48 mil e mais 3,5 mil seriam fechados este ano. A população pulou de 80 milhões para 180 milhões. Aritmética simples: o equivalente àqueles 120 mil seriam, hoje, 270 mil; como restavam 48 mil, então $82 \%$ dos leitos desapareceram. O que se construiu de alternativa? $\mathrm{Na}$ página do Ministério, é possível descobrir que temos 2.000 leitos psiquiátricos em Hospitais Gerais. Desmontou-se parte da rede hospitalar ruim, às vezes depósitos, às vezes asilos - às vezes hospitais - e substitui-se por 2.000 leitos psiquiátricos em Hospitais Gerais e 450 CAPS (fora aqueles para crianças e adolescentes e para álcool e drogas). Onde foram parar as pessoas "desinternadas", os novos doentes graves e o dinheiro? Tenho sérias críticas a essa política irresponsável. Houve imprevidência e tentou-se resolver "revolucionariamente" uma questão muito complexa, que não é única do Brasil. Em outros países, essa forma de enfrentar o problema não deu certo. Não se desconhecia aqui o que ocorreu nos Estados Unidos com a des-hospitalização. Franco Rotelli, quando esteve no Brasil, na década de 1980, disse que o modelo italiano era muito diferente do modelo americano. Segundo ele, o modelo americano resultou nos "loucos pelas ruas", pois os hospitais foram fechados para economizar recursos financeiros, antes de se instalar uma rede alternativa. Ele também afirmou que os centros de Saúde Mental da era Kennedy não davam conta disso.

M. T.: Os loucos americanos, presentemente, estão na cadeia.

V. G.: Os loucos brasileiros nós não sabemos onde estão.

M. T.: Na rua.

V. G.: Não só. Basta conversar com quem trabalha com a população carcerária para saber que há muitos nas cadeias e prisões. As pessoas foram alertadas que não deveriam fazer isso.

* Sic do entrevistado. (N. do E.) 


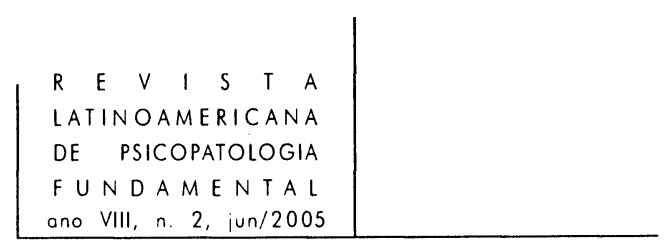

M. T.: Com base na experiência italiana e na experiência norte-americana?

V. G.: O Rotelli disse explicitamente que não poderíamos cometer o erro da política de saúde mental dos Estados Unidos - não poderíamos fechar leitos antes de termos alternativas. Mesmo na Itália, o modelo foi bem-sucedido apenas em alguns lugares. Por exemplo, ao sul da cidade de Verona - não em Verona, mas ao sul da cidade de Verona -, onde há o projeto do Michelli Tansella, fortemente subsidiado por se tratar de um projeto de pesquisa. Eles não precisam de hospital psiquiátrico: a população é relativamente pequena e há leitos em Hospital Geral. Em Trieste, foi parcialmente bem-sucedido. Houve ali características peculiares: uma cidade de 300 mil habitantes, uma sociedade multiétnica e tolerante, onde a população optou por cuidar dos doentes - nada que se possa generalizar. Os textos do Rotelli diziam para não fazermos isso que foi e continua a ser feito aqui. Mesmo assim, o que aconteceu? Os líderes do movimento apregoaram que poderíamos fechar leitos e, "com o dinheiro economizado", abrir os recursos alternativos "mais baratos" e mais humanitários. Mesmo que fosse verdade, mesmo que aquele dinheiro ficasse na área, seria preciso ter equipes e equipamentos eficientes. Depois de vinte anos dessa política, a realidade é a que está aí.

V. G.: Cidade de São Paulo: 10.394 moradores de rua, na parte do município que foi estudada, de acordo com o recenseamento da Fipe (10/2003), segundo a Secretaria Municipal de Assistência Social. Se apenas 10\% dessa população tiver esquizofrenia - como em Juiz de Fora, conforme a tese de doutorado de Uriel Heckert, publicada em 1999 -, então são mais de mil esquizofrênicos nas ruas da Capital de São Paulo. Adianta colocá-los num hotelzinho da Estação da Luz? Adianta tratar como se fosse um problema de habitação? Não adianta: essas pessoas estão doentes. Em termos de ortopedia, isso equivaleria à fratura exposta. Então, temos mais de mil pessoas com fratura exposta nas ruas de São Paulo: qual é o programa que acolhe a demanda dessas pessoas?

M. T.: Segundo a legislação, a responsabilidade é dos CAPS.

V. G.: Então deveria haver uma rede de CAPS eficiente - o que não existe. Os abrigos, asilos e leitos foram fechados e as pessoas deixadas ao relento - como já disse, a população aumentou em 100 milhões, mas o número de leitos foi reduzido e os recursos alternativos são irrisórios.

M. T.: Em São Paulo, a des-hospitalização ocorreu dessa maneira, na sua opinião? Na entrevista que já citei, concedida aqui por Mirsa Dellosi, da 


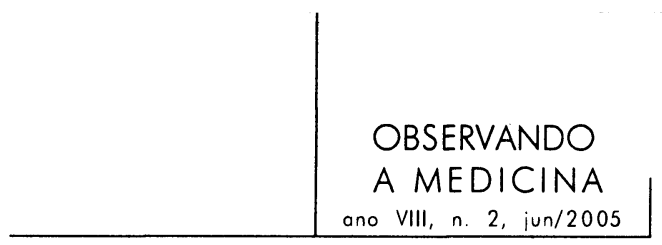

Secretaria Estadual da Saúde, ela afirmou que não houve desassistência nem isso que o senhor chamou anteriormente de "irresponsabilidade".

V. G.: O Governo do Estado de São Paulo foi pressionado a fechar mais leitos, mas se recusou - por saber que não havia onde pôr as pessoas. Descobriu-se que o Estado não poderia despejar os doentes na rua. Entretanto, a maioria dos psicóticos nas ruas de todos os países que fecharam seus leitos nem chegaram aos manicômios; simplesmente não foram atendidos. Isso é desassistência. Mas o que deveria ter sido feito? Fomentar a criação de bons serviços de psiquiatria: de hospitalização aguda; residências terapêuticas - um equipamento caro, mas que pode diminuir a demanda por atendimento hospitalar quando a pessoa não mais precisa de cuidados intensivos. Mas também se poderia ter criado asilos e abrigos para habitação, condomínios supervisionados, que são equipamentos sociais. E você não escapa da necessidade de institucionalização. Quem diz isso é Stefan Priebe, em editorial na Acta Psiquiátrica Escandinávica, em 2004. Os projetos de desinstitucionalização esbarram no contingente de doentes mentais mais graves, que não conseguem viver sem uma supervisão institucional. Isso a Secretaria Estadual da Saúde reconheceu, e em São Paulo houve mais prudência nos últimos anos. Mas se o cuidado deve ser institucional, qual será o equipamento adequado para dar habitação a quem não precisa mais de hospital? Não é residência terapêutica, e obviamente não é CAPS.

M. T.: Por que não é residência terapêutica?

V. G.: A residência terapêutica é um equipamento quasi-hospitalar. É um lugar ainda de tratamento. Mas os doentes mentais mais graves precisam de residência supervisionada, onde sejam ajudados a resolver pequenos conflitos, a resolver as dificuldades que têm para viver sozinhos. Isso deveria ser feito não com verbas da Saúde, mas da área de Bem-Estar Social. Nada é mais difícil para as pessoas comprometidas por psicose ou alguns outros transtornos psiquiátricos do que entender a lógica da sociedade: são explorados, entram em conflito com os vizinhos, com a polícia, são vítimas da dificuldade de compreensão sobre as regras do jogo social. Precisam de alguém que intermedeie - e isso é institucional. Já houve a fantasia de que a desinstitucionalização seria possível. De acordo com o muito informativo livro Loucos pela vida, de Paulo Amarante e colaboradores, a proposta para o Brasil era desinstitucionalizar, desconstruir a doença mental como um problema médico e vê-la como um problema psicossocial. A razão de se usar a palavra manicômio para designar qualquer hospital psiquiátrico, por exemplo, foi uma decisão estratégica para identificar todos os serviços hospitalares com os manicômios judiciários. Mas o que aconteceu? Em vez de desinstitucionalização, houve desospitalização, aquilo que Rotelli condenou nos Estados Unidos. No mínimo, isso foi uma aventura irresponsável. 


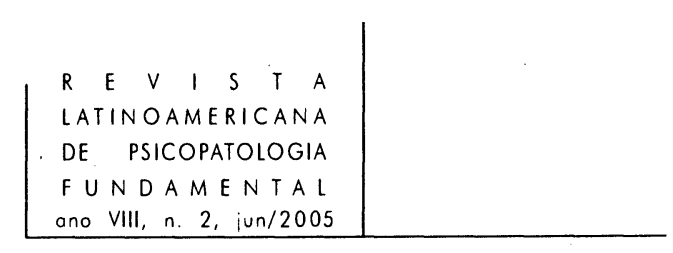

M. T.: Qual é a diferença entre des-hospitalizar e desinstitucionalizar?

V. G.: Para desinstitucionalizar, as propostas seriam ainda mais radicais: os pacientes deveriam se tornar autônomos. O que houve, na melhor das hipóteses, foi trans-institucionalização: a pessoa saiu do hospital para ir para o CAPS, que é uma instituição. Um artigo no British Medical Journal, em novembro de 2004, demonstra trans-institucionalização e aumento da população carcerária doente mental em seis países da Europa, inclusive na Itália. Estamos, de fato, incapazes de desinstitucionalizar. Por quê? Porque, diferentemente de 1960, não temos nenhuma dúvida de que essas são doenças médicas incapacitantes. O pós-guerra trouxe a expectativa de que, através de intervenções psicossociais, haveria prevenção em todos os níveis, inclusive na reabilitação dos doentes mentais. Com a indisponibilidade de qualquer tratamento médico eficaz para esse tipo de problema - não existia nada, a não ser o eletrochoque - todas as fichas foram colocadas na chamada abordagem social-comunitária, de inspiração psicodinâmica. O principal articulador nos Estados Unidos foi Gerald Caplan. O problema é que nada daquilo foi submetido a teste de eficácia - era intuitivamente correto, lógico, dentro dos conhecimentos da época, só que acabou prometendo mais do que podia fazer. As promessas do movimento psicodinâmicopsicossocial-comunitário e da "psicanálise nas instituições" não puderam ser cumpridas. Quais eram elas? Em famílias saudáveis, não haveria doentes mentais; em uma sociedade solidária, haveria menos problemas psiquiátricos. Esqueceuse a dimensão médica, biológica, conhecida desde o Velho Testamento, porque as pessoas têm doenças e não apenas "sofrimento psíquico".

M. T.: "Apenas" sofrimento psíquico?

V. G.: O sofrimento psíquico é universal. É necessário sair da ambigüidade para que a psiquiatria não perca a identidade. Se vamos falar de sofrimento psíquico, prefiro Dostoiévski, Proust, Thomas Mann - essas pessoas falaram de sofrimento psíquico muito melhor do que qualquer psiquiatra. O domínio do sofrimento psíquico é da humanidade. Quem faz melhor a abordagem disso são escritores, poetas, filósofos, não são os médicos, psicólogos, psicanalistas e psiquiatras. Falar em sofrimento psíquico é inespecífico demais. É a mesma coisa que falar em humanização. Por acaso nós somos veterinários? O que estou dizendo é que o sofrimento psíquico não é um problema médico. Se se fala em sofrimento psíquico, não se fala daquilo que identificamos como "anormal", "doente", e que hoje tem tratamento eficaz. Isto é negligência, omissão de socorro, anti-ético. Estou falando de esquizofrenia e outras doenças graves. Em 2005, a eficácia da psiquiatria é comparável à das outras áreas da medicina; só que o modelo montado ou não leva em conta essa eficácia, ou é ambivalente em relação às abordagens médicas e tenta contrapô-las à "reabilitação psicossocial" ou à "escuta", em vez 


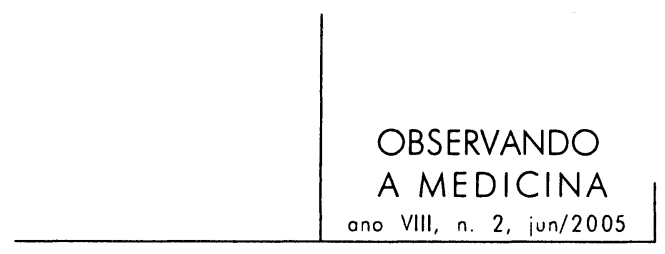

de investir na prevenção secundária eficaz. Além disso, como já disse, o modelo não pode ser só voltado para as psicoses, deixando de lado os transtornos mentais comuns. Agora, se há sofrimento psíquico e não há problema médico, então a pessoa pode se beneficiar de outras alternativas para o alívio da dor psíquica uma boa relação afetiva, uma abordagem religiosa, um consolo na filosofia; ou merecer um tratamento específico, uma psicoterapia, por exemplo; se quiser se conhecer mais profundamente, entender a origem dos conflitos, se quiser um referencial mais robusto, mais sólido, faz como eu fiz algumas vezes: vai para a análise.

M. T.: O senhor se submeteu à psicanálise?

V. G.: Um pouco; o suficiente para ter uma vivência do que é a psicanálise. Sou casado com uma analista.

M. T.: Qual é então o lugar da psicanálise, quando se trata do sofrimento psíquico?

V. G.: A psicanálise tem indicações específicas; eu encaminho pacientes para psicanálise. Existem angústias, conflitos, relações interpessoais estressantes, distúrbios de identidade, problemas de escolha de caminhos existenciais. Não há nada melhor do que a psicanálise para isso. As pessoas pensam que falar de psicanálise é como falar de religião, é necessário louvar o tempo inteiro. Eu não louvo; isso não é religião.

M. T.: Como foi a des-hospitalização nos Estados Unidos?

V. G.: Isso é contado no livro Madness in the Streets - How Psychiatry and the Law Abandoned the Mentally Ill (Loucura nas ruas - Como a psiquiatria e a lei abandonaram os doentes mentais), escrito pela socióloga Rael Jean Isaac e pela escritora Virginia Armat. É lamentável que esse livro de 1990 não tenha sido traduzido para o português. Ali se contam, também, fatos conhecidos de outras publicações: a partir dos movimentos de higiene mental e de saúde pública, sob influência da psicanálise dos anos 1940-1950 e da psiquiatria comunitária de Gerald Caplan, as pessoas pensaram que seria possível resolver problemas psiquiátricos com boa intervenção psicossocial. Não funcionou: os leitos foram fechados nos Estados Unidos e, em 2003, havia quase um milhão de doentes mentais graves no sistema penal - 284 mil presos com esquizofrenia e transtorno bipolar, outros 550 mil em liberdade condicional, além de 200 mil morando nas ruas - conforme o McMan's Depression and Bipolar Weekly, na Internet.

M. T.: A idéia norte-americana foi substituir o hospital por... 


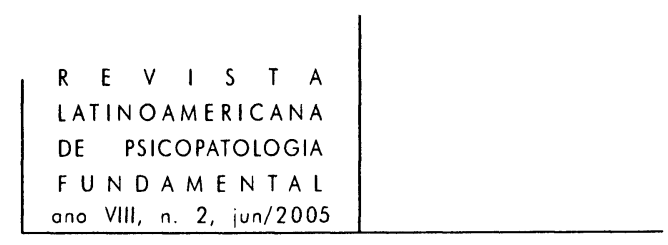

V. G.: Psiquiatria comunitária. Na era Kennedy, esperava-se que Centros de Saúde Mental fossem dar conta de tudo.

M. T.: É a mesma idéia em que se baseia a experiência italiana?

V. G.: Na teoria, não. Segundo os italianos do movimento basagliano, o objetivo dos americanos era meramente econômico: queriam continuar institucionalizando, mas de uma forma mais barata, para investir menos recursos na Saúde Mental, enquanto eles, basaglianos, faziam isso de forma muito mais humanitária, sem preocupação com a economia, e sim com a re-inserção social dos pacientes. Todas as análises sobre a psiquiatria italiana vão mostrar que em alguns centros isso ocorreu: mas não na maioria do país.

M. T.: A expressão "reabilitação psicossocial" nasce quando e como?

V. G.: Existe uma Associação Mundial para Reabilitação Psicossocial, recente, promovida por Benedetto Saraceno, e uma Associação Internacional de Serviços de Reabilitação Psicossocial, mais antiga. Não sei se se fundiram. Esse é um conceito desenvolvido a partir do pós-guerra. No Brasil, seus líderes vêm dos movimentos de Reforma Sanitária, da Saúde Mental/Pública/Coletiva, da Psiquiatria Comunitária, da Terapia Ocupacional. Ela sofre influência conjunta de teorias sociológicas e de base psicanalítica. Por exemplo, em 1978, houve um Primeiro Congresso Brasileiro de Psicanálise de Grupos e Instituições. Segundo o livro do Paulo Amarante, esse congresso estava "inserido na estratégia para o lançamento de uma nova sociedade psicanalítica de orientação analítica institucional, o Instituto Brasileiro de Psicanálise de Grupos e Instituições”. Isso possibilitou a vinda ao Brasil dos principais mentores da rede alternativa da psiquiatria do Movimento de Psiquiatria Democrática Italiana - Franco Basaglia, Felix Guattari, Roberto Castel, Ervin Golfman, entre outros. Depois disso aconteceu a Feira da Psicanálise num congresso no Copacabana Palace. Obviamente essas pessoas não fazem parte das sociedades de psicanálise e nem sei se isso vingou. Mas, em setembro de 2004 no Hospital Juliano Moreira, de João Pessoa, houve um curso de extensão sobre "A Psicanálise e a Reforma Psiquiátrica Brasileira", ministrado por um psicanalista da UERJ, discutindo "o paradigma da desmedicalização e a concepção da loucura como efeito dos processos de exclusão social". Algumas pessoas continuam a contrapor um modelo psicossocial ao modelo médico. Entretanto, algumas propostas da reabilitação psicossocial são interessantes, e as adotamos aqui no Instituto de Psiquiatria da USP. Gosto, em particular, do fomento a empresas sociais.

M. T.: Então na base da reforma... 


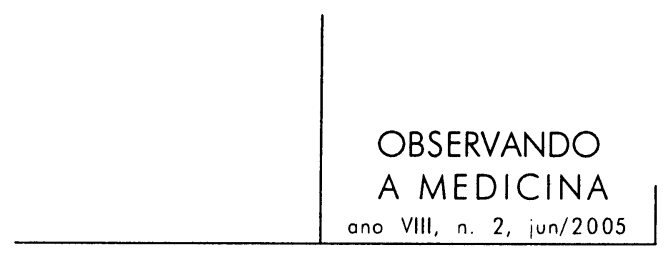

V. G.: ... há um conflito ideológico. Aliás, três conflitos ideológicos básicos. Autores ingleses citam como um dos pressupostos dos basaglianos a idéia euromarxista de que a psiquiatria é um instrumento do capitalismo. O outro conflito contrapõe psiquiatria clínica, mais médico-biológica, e os movimentos de higiene mental e psicossomático, de inspiração psicanalítica, para os quais as alterações psiquiátricas seriam reações a problemas e conflitos intrapsíquicos ou interpessoais, mas as insere também num contexto político-social ao falar da sociedade hostil, "desigual, intolerante para os seus homens e suas idiossincrasias". A psiquiatria psicodinâmica era, até 1976, a forma dominante nos departamentos de psiquiatria dos Estados Unidos. Se as alterações psiquiátricas eram reações psicológicas, seu corolário seria poder intervir precocemente, com ferramentas psicossociais, para a prevenção de doenças mais graves.

\section{T.: Tornando o ambiente não hostil?}

V. G.: Ou então fazendo com que a pessoa se tornasse mais capaz de enfrentar essa hostilidade sem se desestruturar.

M. T.: A que esse entendimento se contrapõe?

V. G.: A todo o avanço que aconteceu na psiquiatria como especialidade médica, de 1960 para cá, fortemente subsidiado pelos recursos terapêuticos eficazes. Até o início dos anos 1950, não havia nada com que intervir dentro do modelo médico; você não podia fazer um diagnóstico, dar um medicamento e obter uma resposta previsível. Isso permeava a psiquiatria como um todo, e o psiquiatra era quase um botânico, discutindo suas classificações e teorias psicopatológicas. Quando comecei a falar sobre síndrome do pânico, as pessoas diziam que era um modismo, que o pânico era a neurose de angústia de Freud. Insisti que era, sim, a neurose de angústia de Freud e não a "neurose ansiosa", como se usava nas classificações da época, que englobava a ansiedade generalizada. Pânico é uma condição específica, como Freud percebeu em 1895, com Catarina. É fantástico; uma descrição muito pertinente de síndrome do pânico com agorafobia secundária. Freud dizia que, um dia, o quadro seria tratado com medicação. Há alguns anos, conversei com um dos psiquiatras que mais estimo e respeito em São Paulo, de orientação mais psicodinâmica do que a minha, que sou de maior formação farmacológica. Disse a ele: "Proponho tratar esta nossa cliente desta forma; espero, daqui a duas semanas, ter tal resposta". Ele respondeu: "Vamos ver o que vai acontecer, mas não espero que isso aconteça". Duas semanas depois, aconteceu o que eu previra. Para mim, não foi surpresa; psiquiatria é medicina, e como em qualquer outra área médica, a partir de um diagnóstico, há uma 


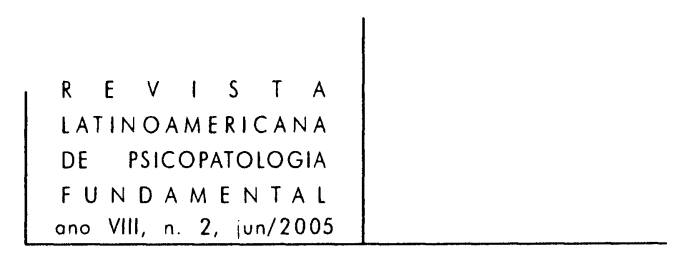

formulação clínica, propõe-se uma conduta terapêutica, e espera-se um determinado resultado dentro de um prazo determinado. Isso não é nada além de medicina; em todas as áreas é assim. Esse contraponto virou uma questão ideológica, em vez de ser uma questão técnica; psiquiatria biológica e psiquiatria psicodinâmica são reducionismos indesejáveis.

\section{T.: Por quê?}

V. G.: Porque as abordagens devem ser complementares. Vivemos num mundo dualista e reducionista. Para fazer pesquisa pode ser impossível escapar de reducionismos metodológicos. Em psicanálise, deve-se ficar no referencial psicanalítico; em biologia molecular, é preciso ficar na biologia. Toda vez que se tenta fazer pontes, corre-se o risco de cair porque não há elementos estruturais para fazer essas pontes. A literatura recente na interface de neurociências e psicanálise é muito interessante, mas mostra que ainda não há elementos sólidos para sustentar uma ponte. Obviamente, há uma fertilização cruzada de conhecimentos, mas deve-se abandonar esse dualismo metodológico e fazer uma abordagem integrativa na hora em que se chega ao paciente. Porém, além disso, existem questões político-ideológicas e corporativas. Uma publicação do Conselho Federal de Psicologia mostra isso; aliás, o CFP é muito alinhado com o "Movimento da Luta Antimanicomial". A publicação dos anais de um Fórum Nacional, de 31 de maio de 2000 - "Como anda a Reforma Psiquiátrica Brasileira" - traz citações nominais a mim. Por exemplo, David Capistrano, falecido precocemente, diz: [lê] "A meu ver, respondendo a uma indagação dos organizadores do Fórum, há dois grandes inimigos para o movimento de reforma... o Sindicato dos Donos de Hospitais, Federação dos Hospitais e outras entidades, e um pensamento acadêmico, biologicista, reducionista, que levantou novamente a cabeça nas nossas instituições universitárias, cuja ponta de lança é a psiquiatria na Faculdade de Medicina da Universidade de São Paulo, o professor Valentim Gentil e seu bando. Isso se constitui num obstáculo e num centro de difusão de um pensamento hostil à reforma psiquiátrica em nosso país, que não podemos subestimar. Isso tem se espraiado por várias entidades de representação corporativa da categoria médica, que em nenhum lugar do mundo foi favorável à reforma psiquiátrica, pelo menos como maioria sólida, e tem uma influência considerável". Tirando a grosseria, essa me pareceu uma avaliação lúcida dele. De fato, existem dois conjuntos principais de opositores - um, que representa os interesses dos hospitais, e, outro, as Universidades e as representações dos médicos, em todos os níveis. Por que essa segunda fonte de resistência? Porque o viés da reforma psiquiátrica é claramente anti-médico, pretende desmedicalizar as doenças mentais. Não tenho nada contra desmedicalizar problemas - desde 


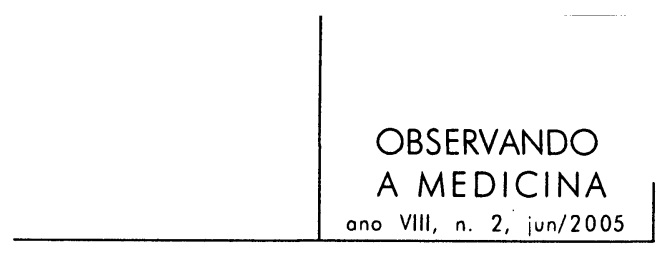

que se encontre alguma ajuda melhor do que a abordagem médica para eles. Tenho responsabilidade social, ética, pessoal, de cidadão, de dizer que esses são problemas médicos, da esfera da psiquiatria. Uma assessora do Domingos Sávio uma vez perguntou se eu achava que os psiquiatras entendiam mais de saúde mental do que os outros profissionais. Respondi que sim, porque os psiquiatras sabem o que é doença. Não se pode falar de saúde sem saber o que é doença.

\section{T.: E o que é doença?}

V. G.: É um conceito arbitrário, uma convenção. Certo. Mas é uma convenção útil para quem a sofre. É tudo aquilo com consistência para que se consiga identificá-la com robustez sindrômica; que, em geral, se repete em diferentes épocas, em diferentes culturas, em diferentes condições; que faz parte da espécie em estudo - pode ser doença de planta, ou de gente -; que é lesiva para a integridade do indivíduo; que interfere significativamente com a vida, o bem-estar e a capacidade de exercer suas funções; e que pode ter tratamento específico. Em psiquiatria, encontramos doenças conhecidas desde a Bíblia, como a depressão e o transtorno bipolar. No Velho Testamento, lê-se textualmente: "Então, fulano ficou louco", "fulano está delirando", "fulano teve um acesso de fúria e matou bois", "fulano foi tomado por uma influência divina que o deixou deprimido", e daí por diante. Estados semelhantes aos que encontramos em diferentes partes do mundo, em diferentes culturas, conhecidos há séculos, não podem ser apenas decorrentes de conflitos ou situações sociais. Têm que decorrer de uma disfunção específica do corpo humano.

M. T.: Novamente: Mas não há aí um sofrimento psíquico?

V. G.: Se eu fosse dualista, teria que tratar o psiquismo como algo separado.

M. T.: Do quê?

V. G.: Do físico. Pode-se trabalhar com o dualismo, se você pensar em alma. Dualismo interacionista, por exemplo. Mas não se pode trabalhar com o dualismo se você pensar em psíquico e biológico - não consigo pensar em nada que não seja biológico que tenha psique; não consigo imaginar psique sem biologia; nem imaginar a psique dos metais ou dos minerais. Não sou animista. Tento não ser dualista na clínica. Imagino que pessoas em coma possam até ter alguma vida psicológica; mas os mortos não. Não acredito em algo psicológico que tenha a ver com vidas passadas. Temos evidências muito seguras do papel da genética, de alterações na fisiologia corporal, até de alterações micro-anatômicas no cérebro de portadores das principais doenças mentais. Não há como considerá-las psicogênicas. Isso não quer dizer que não existem componentes ambientais e 


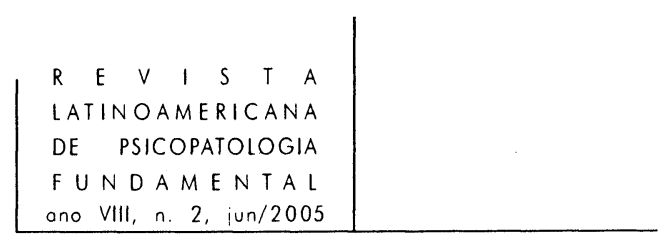

estresse psicossocial participando da vulnerabilização, precipitação, manutenção, agravamento ou melhora e remissão desses quadros. Os componentes causais podem ser numerosos e temos que trabalhar com mecanismos complexos, inclusive na prevenção.

M. T.: O que leva, na sua opinião, os adeptos da reabilitação psicossocial negarem esse aparato de conhecimento?

V. G.: A negação não vem da reabilitação psicossocial; ela é remanescente do movimento antipsiquiátrico. A reabilitação psicossocial tem aspectos interessantes. Para promover a reabilitação psicossocial, não é necessário desconstruir a psiquiatria, não é necessário "libertar a identidade" e dizer que a psiquiatria é uma farsa, uma ideologia, uma disciplina inexistente, como sustenta Benedetto Saraceno. O viés antipsiquiátrico tem também um componente corporativista. Qual é a origem do movimento da luta antimanicomial? Segundo Paulo Amarante, ele começa como um Movimento dos Trabalhadores em Saúde Mental. Em 1978, na chamada "Crise da DINSAM", essas pessoas estavam lutando por melhores condições de trabalho, por poder exercer melhor a sua arte, serem mais bem remuneradas, mais bem treinadas, para terem mais poder.*

M. T.: Quem eram esses "trabalhadores da saúde mental"?

V. G.: Jovens psiquiatras que estavam empregados em hospitais da DINSAM no Rio, com bolsas insuficientes, sobrecarregados; enfermeiros, psicólogos, assistentes sociais, estudantes universitários, médicos. Era o fim do regime militar, e o movimento de trabalhadores, querendo melhores condições de trabalho, tornou-se um momento de confronto social. Não foi um movimento de pacientes, nem para fechar hospital, para fechar manicômio: foi um movimento de trabalhadores, corporativo, de luta social. Quer dizer: "Vamos tirar um pouco da autoridade desses dirigentes de hospitais, desse governo autoritário, desse Ministério da Saúde, e vamos aproveitar para tirar um pouco do poder dos médicos mais graduados das instituições universitárias". Todo o movimento da reforma psiquiátrica brasileira passa à margem da Universidade. Por quê? Pela mesma razão que a Associação Brasileira de Psiquiatria saiu das mãos dos catedráticos - porque os jovens dessa época, todos nós, queríamos mais autonomia, mais poder. O que acontece quando, em 1984, seis anos depois, se

* Os trabalhadores da Dinsam - Divisão Nacional de Saúde Mental do Ministério da Saúde no Rio de Janeiro, em 1978, teriam sido desencadeadores do futuro movimento antimanicomial ao denunciar as más condições de quatro hospitais psiquiátricos do Estado, de acordo com a versão apresentada comumente por autores ligados ao movimento. (Nota do E.) 


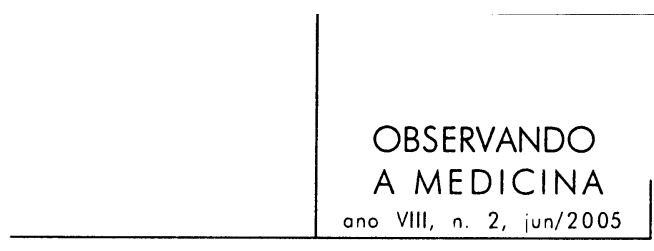

constitui o movimento da Luta Antimanicomial? Decidiu-se que era hora de não apenas defender melhores condições de trabalho, melhor remuneração, mais poder para os não-médicos da equipe, mais autonomia para escolher tipos de conduta terapêutica - acrescentou-se a tudo isso a idéia de fechar algumas das péssimas instituições; serviram-se então do movimento basagliano (da Lei 180 de 1978 na Itália), para negar a psiquiatria. Quem visitava a maioria dos hospitais psiquiátricos brasileiros da década de 1970 tinha mesmo vontade de fechá-los. Aqui no Instituto de Psiquiatria, em 1990, apresentavam-se para nós duas opções: fechar ou modernizar. Modernizamos. Quando somos mais jovens, é mais fácil demolir; se tivessem se preocupado com o custo social, provavelmente teriam percebido que melhor seria readequar algumas das instituições. Mas a época era de revolução; uma revolução não-sangrenta, exceto para os pacientes e para as famílias. Esse movimento se torna "Movimento da Luta Antimanicomial" e sua bandeira passa a ser o fechamento dos hospitais. O que está por trás disso continua sendo a mesma coisa: melhores condições de trabalho, mais poder, mais direito de dizer o que fazer para cada paciente, condições mais agradáveis de trabalho. Quais são essas condições mais agradáveis? Desconsidera-se os casos mais complicados e mais difíceis, como se eles não existissem; seleciona-se os casos mais adequados para o modelo que a equipe pretende seguir; propõe-se atividades em grupo para ajudar criativamente essas pessoas a se sentirem melhor; também o profissional de saúde procura se sentir mais feliz, realizado e, de preferência, mais bem remunerado. Quem fala isso sobre os centros italianos não sou eu. É Kathleen Jones, Professora Emérita de Política Social na Inglaterra. Ela visitou os serviços: atendiam neuróticos e psicoses leves, em grupo, em psicoterapia, ambientes assépticos, algumas horas por dia, bem remunerados. Não é uma maravilha? O que aconteceu, na Itália, em muitos centros comunitários, foi que eles só ficaram com os casos de que podiam dar conta.

M. T.: O senhor acha que é isso que acontece nos CAPS?

V. G.: Com exceção da remuneração. Você tem alguma dúvida?

M. T.: Eu não sei.

V. G.: Vá a um CAPS, veja quantos pacientes estão amarrados na cama. Nenhum.

M. T.: $E$ isso não é bom?

V. G.: Isso quer dizer que paciente psiquiátrico não precisa ser amarrado na cama? Não. Quer dizer que o paciente que precisa ser amarrado na cama, enquanto o medicamento não funciona, não está no CAPS. Onde ele está? Ou em algum manicômio residual, ou num pronto-socorro, ou preso, ou com alguma família 


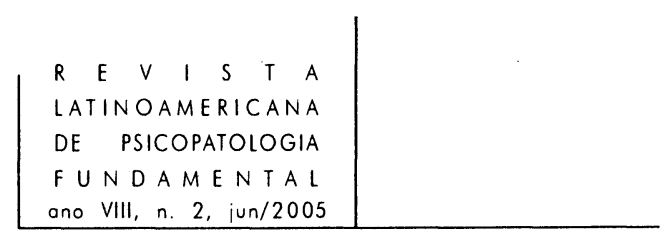

que o mantém em casa, a duras penas para ambos. A maioria dessas pessoas não entra nas estatísticas. Elas não existem. Quando estão nas ruas, passam a fazer parte da paisagem. Outro dia, entrevistei o senhor Raimundo. Conhece o senhor Raimundo? Você conhece: é aquele senhor que fica na Pedroso de Moraes*, sentado naquela esquina, escrevendo. Ele está lá, segundo me disse, há mais de dez anos. Olhando, dá a impressão de que não toma banho. Se ele te der uma folhinha de papel, será mais branca do que essa do seu caderno. Ele escreve frases, sem maior coerência ou conteúdo. O bairro todo passa pelo lugar do seu Raimundo, dá água, comida. Só que o seu Raimundo está psicótico, há muitos anos, e está na rua. Há outros psicóticos que, de repente, podem se tornar violentos devido a delírios ou alucinações. Uma vez, visitando o Juqueri, vi um paciente amarrado na cama porque avançava nos olhos ou nos testículos - de outras pessoas, ou dele mesmo. Esses indivíduos existem, e não vão para os CAPS; estão doentes e não estão sendo atendidos adequadamente.

M. T.: $O$ que o senhor propõe?

V. G.: Nem nos hospitais psiquiátricos mais modernos há equipe e ambiente adequados para atender esses doentes. Não necessariamente há uma solução para isso: quando a situação é muito grave, ou ela é enfrentada, ou as pessoas vão continuar como estão até morrer. É revoltante que o movimento antimanicomial finja que não existem situações como essas, simplesmente porque não são freqüentes; ou, quando vêm a público, que se culpe a psiquiatria pela falta de atendimento adequado ou pela sua própria existência. O que é necessário para enfrentar uma situação dessas? Em princípio, identificar quantas pessoas estão assim; ter um centro de cuidados intensivos, onde essas pessoas possam ser avaliadas, estudadas, e se desenvolva uma tecnologia para atendê-los. É necessário acompanhar o que se faz no mundo com pessoas nessas condições. Estou propondo à Secretaria da Saúde de São Paulo a criação de um centro assim num dos hospitais do Estado, com equipe altamente qualificada para receber essas pessoas e investigar o que fazer com elas.

M. T.: Mas quem são essas pessoas?

V. G.: São psicóticos graves, alguns deles com quadros orgânicos, com problemas neurológicos.

* A Pedroso de Morais é avenida de grande circulação em bairro abastado de São Paulo; Raimundo tem sua casinha de madeira no canteiro central da avenida. (Nota do E.) 


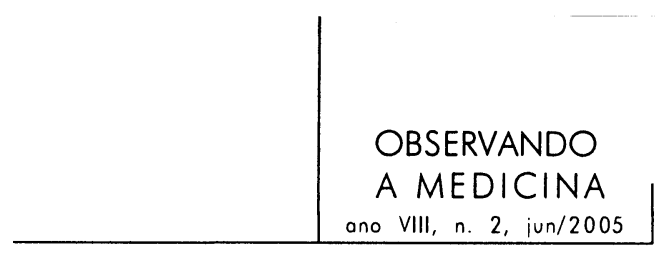

M. T.: $O$ que é um psicótico grave?

V. G.: Que tal um que pensa em arrancar os próprios olhos, por exemplo, isso é grave, não é? Conhecemos vários que já fizeram isso.

M. T.: Então o seu critério é a possibilidade de causar dano, para outro ou para si próprio.

V. G.: Imagine que ele ouve uma voz. Essa voz diz para ele seguir algo escrito em algum livro religioso. Por exemplo: ao ver algo de condenável, ele tem que arrancar os próprios olhos. Não faltam textos para sugerir esse tipo de coisa. Ou que tal o caso da enfermeira norte-americana Andrea Yates, que afogou seus cinco filhos na banheira? Sofria de depressão psicótica pós-parto, foi tratada com antidepressivos de penúltima geração. A indicação específica para ela teria sido eletroconvulsoterapia; mas, no Texas, fazer ECT é muito complicado. Recebeu alta; em casa, quando o marido foi trabalhar, afogou todos os filhos, um atrás do outro; depois telefonou à polícia, e esperou ser presa. Foi condenada à prisão perpétua. O marido a defendeu no tribunal. Minha pergunta é: quem deveria ser condenado? A sociedade do Texas.

M. T.: O senhor afirma então que no modelo de Saúde Mental preconizado pelo Sistema Único de Saúde, essas pessoas não podem ser tratadas.

V. G.: Obviamente, elas precisam de tratamento médico ultra-especializado. Num caso como o de Andrea Yates (e eles existem aqui), é necessário um centro capaz de fazer eletroconvulsoterapia, sob anestesia, com cuidado intensivo. Onde é possível fazer isso na rede pública no Brasil? Em alguns centros universitários e em poucos hospitais públicos. Tente fazer isso fora daí. Em primeiro lugar, o ECT não é remunerado pelo SUS. Por isso, alguns hospitais filantrópicos o aplicam, mas sem as condições técnicas adequadas. Tente regulamentar isso. Participei de uma audiência pública na Câmara Federal; estava lá o autor de um projeto para regulamentar o ECT, o Deputado Marcos Rolim. Levei um vídeo para mostrar como se faz ECT aqui no Hospital das Clínicas: uma senhora idosa entra, deita, põe os eletrodos de monitorização, é anestesiada, faz a convulsoterapia, levanta, toma café e vai embora para casa - a maior parte dos nossos clientes são ambulatoriais. Surpresa na platéia: "quer dizer que não é na marra, 450 volts, passando uma motocicleta por cima das pessoas?" Não. O ECT é um procedimento médico que salva vidas. No caso da Andrea Yates, poderia ter salvo a vida de cinco crianças e a dela. Só que, na Câmara Federal, os médicos foram contra, por considerarem o projeto uma intervenção na autonomia do médico; o Conselho Federal de Psicologia foi contra, porque não quer que a eletroconvulsoterapia seja reconhecida pelo SUS. Um absurdo. O projeto foi 


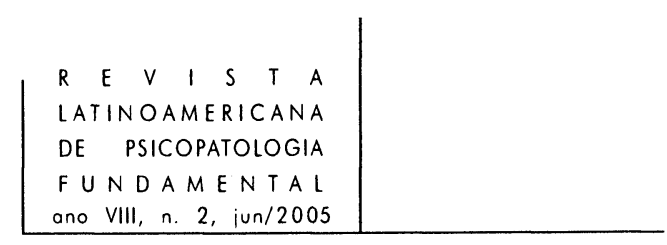

rejeitado; consequientemente, até hoje a rede não tem como atender casos como o de Andrea Yates. O que é isso?

M. T.: Um momento. Na proposta da Reforma Sanitária da Saúde Mental, não se leva em conta a existência dessas pessoas? Ou eles acham que é possível dar conta delas no ambiente do CAPS?

V. G.: Todos sabemos que essas pessoas não podem ser atendidas nos CAPS, a não ser que o CAPS se torne uma unidade de cuidados intensivos em psiquiatria.

M. T.: No modelo, os CAPS 24 horas deveriam ser capazes de acompanhar casos graves durante até cinco dias. Prevê-se que a pessoa não saia do CAPS no período.

V. G.: Isso que você descreve chama-se "hospital psiquiátrico de agudos".

M. T.: Tenho notícia de que esse parece ser um problema bastante concreto no modelo: não há lugar para agudos.

V. G.: Agudos precisam de Unidade Psiquiátrica. Chega uma certa hora em que não se pode negar assistência; em cinco dias, o caso do seu Raimundo ou o de Andrea Yates não se resolvem. Mas eles não têm que ficar num manicômio.

M. T.: O hospital psiquiátrico não pode ser substituído pela enfermaria psiquiátrica no Hospital Geral?

V. G.: A enfermaria psiquiátrica no Hospital Geral é útil, principalmente em regiões em que não se pode ter uma instituição mais sofisticada. Há entre essas enfermarias aquelas que são manicomiais. Por quê? Por misturar patologias num mesmo ambiente; por não ter equipes com o número de funcionários e a competência técnica necessários. A remuneração do leito psiquiátrico pelo SUS não é compatível com a manutenção de um serviço adequado. Os casos mais graves deveriam ser remunerados como Alta Complexidade.

M. T.: Mas essas enfermarias são pequenas. Falta a elas essa característica de imensidão do que é chamado de manicômio.

V. G.: A lógica é manicomial: uma equipe mal treinada lida simultaneamente com doenças diferentes. Não adianta dizer que as enfermarias psiquiátricas da Unicamp, de Ribeirão Preto, da Escola Paulista de Medicina, do Servidor Estadual, ou a da Universidade Federal do Rio Grande do Sul - as melhores que temos dão conta de tudo. Eles não podem atender vários casos muito graves. Em uma delas, não se podem atender homens. Precisaríamos de muitas unidades psiquiátricas no Hospital Geral. Como se faz para não ficar manicomial? Pode- 


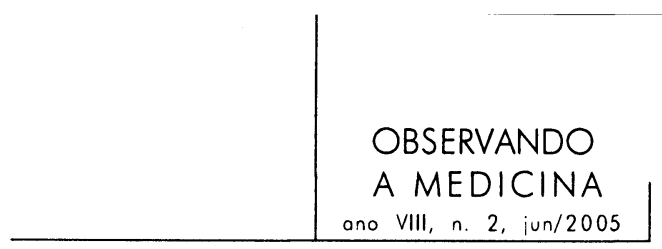

se, por exemplo, criar unidades psiquiátricas especializadas em determinados tipos de problemas afins, em diferentes hospitais gerais. Por exemplo, uma para esquizofrenia e transtornos psicóticos ou afins, outra para transtornos ansiosos e do humor, outra para casos geriátricos, outra para anorexia nervosa e distúrbios alimentares, uma para crianças e adolescentes, outra para dependências e descontrole dos impulsos, em diferentes hospitais gerais.

M. T.: Cada um no seu escaninho. Mas esses são casos graves?

V. G.: Podem ser e cabem unidades psiquiátricas sub-especializadas para casos agudos que precisam de hospitalização em cidades grandes, como Rio de Janeiro, São Paulo, Salvador. Mas não é o caso de se fazer isso numa cidade de porte médio, porque não haverá as diferentes equipes. Recebendo diárias de $\mathrm{R} \$ 37,00$, qual é o Hospital Geral que abrirá leito psiquiátrico, ao invés de leito cirúrgico de alta complexidade? Resposta: só os hospitais gerais públicos, sempre deficitários, nos quais o problema são equipes mal remuneradas. Uma outra crítica aos defensores da reforma - os psiquiatras nela engajados não brigaram pelo essencial: que a psiquiatria de agudos fosse tratada como uma especialidade médica e não como se doença mental fosse uma questão de saúde pública básica, de cuidados primários, ou simples "sofrimento mental". Esse foi um erro tático fundamental para quem queria alternativas como a internação em Hospital Geral.

M. T.: De acordo com os postulados da reforma, isso era estratégico, pois justamente se tratava de diluir o saber próprio do psiquiatra.

V. G.: Isso; para os anti-psiquiatras. Mas do ponto de vista do Ministério da Saúde, da Secretaria de Saúde, psiquiatria deveria ser tratada como a cardiologia, deveriam existir programas de prevenção.

M. T.: O senhor estava descrevendo o seu ideal de hospital psiquiátrico. No que ele é diferente de um manicômio?

V. G.: É um hospital de agudos, especializado, de alta complexidade, que deve funcionar como uma UTI. Um paciente internado num hospital psiquiátrico deve ser tratado intensivamente para abreviar a internação. Nada de ficar em observação de rotina, durante dias, sem ser medicado. O melhor dos hospitais nunca vai ser um lugar agradável. Para quem está com doença mental é pior ainda, porque o paciente já não entende a lógica da instituição. É necessário ter um controle da eficiência e capacidade de adequar o sistema conforme a necessidade de cada paciente. Não se pode simplesmente adotar um procedimento por ele parecer intuitivamente eficaz, ou apenas por ser compatível com uma teoria ou ser bem intencionado. É necessário adotar procedimentos que funcionem. Não vai ser o 


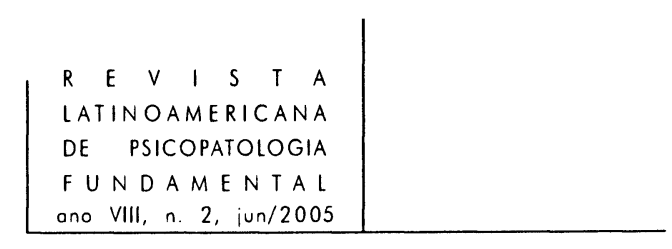

PNASH [Programa Nacional de Avaliação dos Serviços Hospitalares] que vai mudar essas coisas. O texto do PNASH para psiquiatria foi baseado numa pesquisa de satisfação do "cliente externo... no Grupo Hospitalar Conceição" no Rio Grande do Sul. Nada se sabe dessa pesquisa. Imagine se alguém perguntar a um usuário: "Você quer tomar eletrochoque?; quer ser amarrado na cama?; quer tomar remédio sedativo?". Avalia-se assim a eficiência de um sistema? Foi perguntado se a pessoa precisa de ECT; se é preciso ficar temporariamente contido no leito enquanto toma um soro ou espera uma medicação fazer efeito; se tem impulsos agressivos agudos; se precisa de uma medicação sedativa durante algum tempo, para controlar sintomas psicóticos ou agitação? Ao mesmo tempo, o PNASH não serve para remunerar decentemente um serviço melhor. Só é levado em conta para reduzir a diária hospitalar, já aviltante, conforme o número de leitos de uma instituição, independentemente da qualidade dos seus serviços. Isso parece o garrote espanhol. É mais uma forma de fechar leitos e impedir a oferta de serviços hospitalares, adotada desde que o Projeto Delgado foi derrotado, ao não conseguir impor o fechamento obrigatório dos hospitais. Se fosse para aumentar a receita para serviços extra-hospitalares, a estratégia deveria ter sido ir ao Congresso, ao Ministério da Fazenda, dizer: "precisamos de mais recursos para a área de saúde mental; isto aqui causa prejuízos de bilhões de dólares por ano". A verba para a Saúde Mental - R\$600 milhões por ano - é irrisória perto do prejuízo, dos custos indiretos das doenças mentais. O que precisaria ser dito é: "temos hoje boa medicina, boa psiquiatria, boa eficácia, boa prevenção secundária; vamos investir num sistema eficiente, treinar bem as equipes, dar os medicamentos essenciais e diminuir as repercussões econômicas e sociais disso". Mas não é o que acontece. O Ministério vai ao Congresso se vangloriar do fechamento de leitos e promete fazer mais CAPS. Por quê? Como reivindicar psiquiatria de alta complexidade, se o compromisso é com cuidados primários e com o movimento basagliano, que pretende negar a psiquiatria e desmedicalizar os problemas de Saúde Mental? Como dizer que a eletroconvulsoterapia é um procedimento eficaz e seguro, que deve ser utilizado por salvar vidas, que deve ser remunerado para ser bem utilizado, quando os seus aliados querem caracterizar o ECT como tortura? Falávamos de três conflitos...

M. T.: $O$ senhor explicitou dois: socialismo versus capitalismo, psiquiatria dinâmica versus psiquiatria biológica.

V. G.: O terceiro grande conflito é o corporativista.

M. T.: Esse não é exatamente um conflito.

V. G.: É uma briga por espaço e mercado. Em parte, o conflito é entre o modelo de saúde pública e um modelo médico, entre saúde pública e psiquiatria. O principal 


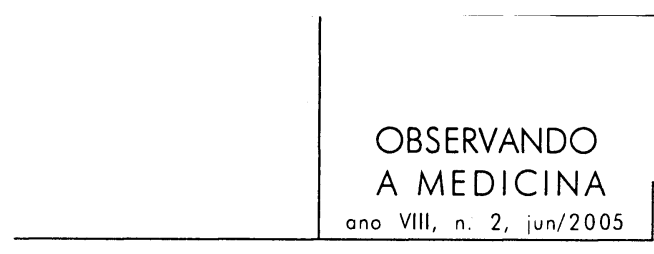

é a disputa entre médicos e outros profissionais de saúde mental. Com frequiência, junto a isso, tem relação com a negação da doença mental, a antipsiquiatria, a anti-instituição psiquiátrica, ou até a defesa da liberdade de ser louco como forma de existir. Existem, por outro lado, sérias críticas aos argumentos de Michel Foucault, feitas por importantes historiadores da medicina, como Roy Porter e Edward Shorter, aparentemente desconhecidos dos que escrevem sobre este tema em nosso meio. Por exemplo, a idéia de "grande internamento" é aplicável, na melhor das hipóteses, somente ao que ocorreu na França, pois os demais países da Europa sequer tinham governos centralizados para fazer isso. Desautorizar Foucault desmonta boa parte dos argumentos sobre as relações da psiquiatria, em sua origem na Europa, com o poder e a repressão aos divergentes. Houve abusos sem dúvida; mas, segundo essas análises, o que estava por trás da instituição dos asilos era a tentativa malsucedida, mas bem intencionada, de acolher e cuidar das pessoas doentes mentais das ruas e prisões (para onde elas voltaram cem anos depois, graças às - talvez bem intencionadas e malsucedidas - reformas dos últimos quarenta anos). A psiquiatria avança no conhecimento desses quadros, estabelece seus diagnósticos e gera-se um outro conflito que persiste até hoje: como delimitar o que se pode chamar de doença. Esbarra-se em perguntas como: psicopatia é doença ou não é?

M. T.: $O$ que é um psicótico? E o que é um psicopata?

V. G.: Os textos nos dizem que o psicótico tem uma quebra no contato com a realidade; o psicopata é um indivíduo com uma alteração na personalidade que o impede de ter uma conduta moral compatível com a da maioria das pessoas. No âmbito da reforma, postula-se representação por organização de pacientes. Dificilmente um grupo de pacientes psicóticos vai poder se organizar para defender bem os seus próprios interesses, devido à doença. Tenho seríssimas restrições à utilização de pacientes como massa de manobra. Já testemunhei isso. Vi grande número de pacientes serem levados a fóruns, conferências, comissões, onde, freqüentemente, não entendiam direito o que se passava: pedia-se o voto deles em propostas que dificilmente poderiam ser compreendidas. Participei de um programa de televisão em que um rapaz estava delirando e uma profissional, muito ativa politicamente, o acariciava, tentava acalmá-lo; mas foi preciso retirálo do estúdio, pois estava muito perseguido. Depois passaram um filme em que ele participava de corridas de saco e com ovo na colher. Isso me revolta. Cadê a Ética, o respeito humano, o direito dessa pessoa de ser preservada? É um indesculpável abuso.

M. T.: Qual deve ser, no seu entendimento, o destino dos CAPS? 


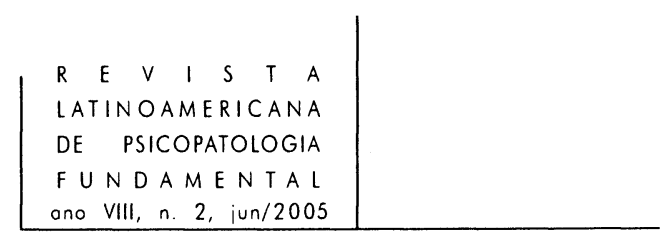

V. G.: Para os CAPS funcionarem bem, devem estar adequados ao local em que se encontram. Em um município de 30 mil habitantes, um CAPS pode ser o centro de triagem e de referência, até estabelecer um programa de reabilitação semelhante ao hospital-dia, por exemplo. O problema é: ele não serve para moradia, nem para hospitalização aguda. Ele serve como centro para coordenar um programa de prevenção em vários níveis. Mas uma coisa é certa: não substitui o hospital e nem o asilo.

M. T.: Qual deveria ser o lugar do psiquiatra nesse CAPS que o senhor descreveu? V. G.: Custa formar um psiquiatra: seis anos de Medicina, dois anos de residência, mais alguma especialização. Como a questão é de saúde pública, o que é melhor: ter um médico generalista com formação básica em psiquiatria numa cidade com 30 mil de habitantes, ou levar um psiquiatra para uma cidade de 30 mil habitantes? Lógico que deveria ser um médico generalista com conhecimento de psiquiatria. Não é necessário ter um psiquiatra em cada CAPS, um psiquiatra em cada cidade. Mas se esse generalista precisar de uma supervisão ou de uma consultoria, então deve haver um psiquiatra a quem ele possa recorrer. Existem perto de nove mil psiquiatras no Brasil. Com 180 milhões de habitantes, não é possível esperar que a assistência esteja centrada no psiquiatra. Mas na hora que houver um problema psiquiátrico mais complexo, dá para transferir a responsabilidade para a equipe multiprofissional? Não dá.

M. T.: Os defensores do modelo atual acham que dá?

V. G.: Sim. Mas os membros das equipes multiprofissionais não têm formação para isso. Como se prova que não têm? Simples: basta pedir que entrevistem dez pacientes e formulem um diagnóstico clínico. Impossível. Mesmo um clínico geral - e muitos psiquiatras que fizeram residência há muito tempo e não se reciclaram, também - não sabe fazer diagnósticos diferenciais. Seria preciso um sistema de educação continuada para garantir qualidade, como se faz em alguns países. O resto é falso: "vamos fazer uma assembléia para decidir se damos alta ou não para uma pessoa". Bonito? Um dia assisti a uma palestra, aqui no Instituto de Psiquiatria, quando contaram uma experiência em que uma decisão dessas foi tomada em reunião de equipe: a opinião do psiquiatra valia quase tanto quanto a da cozinheira do serviço. Eu comentei que quando o psiquiatra e a cozinheira trocam de papéis, quem sofre é a comida. Então, vamos preservar responsabilidades e competências, porque estamos lidando com a vida de uma outra pessoa que está sofrendo; vamos parar de tratar isso como se fosse mais simples do que é, pois não é simples. Tenho 35 anos de psiquiatria, e tenho medo de não saber o que fazer em muitas situações. Como posso esperar que alguém 


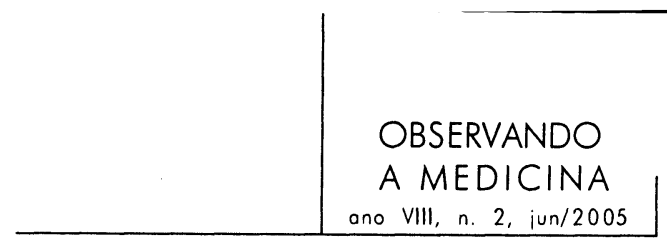

sem vivência, que não conhece a literatura, com formação em área complementar, possa tomar decisões desse tipo? Não posso aceitar. Eu sou médico; agora, toda vez que tiver um parto, vou entrar? Não; não tenho competência para isso. Se as pessoas ficassem dentro da ética, da responsabilidade, da competência e da honestidade, teríamos menos problemas. As pessoas estão correndo riscos desnecessários, e estão fazendo outras pessoas correrem riscos desnecessários.

M. T.: $O$ senhor, ao se contrapor aos partidários da Reforma, defende uma especificidade da psiquiatria frente aos outros profissionais, mas para confundi-la com a medicina.

V. G.: Confundir não, identificar com a medicina. A única coisa que a psiquiatria tem de eficaz é a abordagem médica. É uma especialidade médica, como a neurologia ou qualquer outra.

M. T.: E seu objeto...

V. G.: ... é o indivíduo doente mental, desde as doenças mentais mais leves, como o transtorno de pânico, até as doenças mentais mais graves, até a demência. Quem define melhor a psiquiatria é o maior psiquiatra da Grã-Bretanha, o maior psiquiatra da língua inglesa de todos os tempos, Aubrey Lewis. A definição dele, que eu uso muito: "Psiquiatria é o estudo do comportamento anormal do ponto de vista médico: ela se ocupa com o diagnóstico, o prognóstico, a prevenção e o tratamento."*

M. T.: Não há nada mais próprio à psiquiatria do que ela ser medicina?

V. G.: A psiquiatria é uma especialidade médica, não é outra coisa. Não é psicanálise, não é terapia comportamental, não é psicofarmacologia, não é nada disso. Ou não? Quem disser que não, por favor me conte o que é então a psiquiatria.

* A definição apareceu em "Empirical or rational? The nature and basis of Psychiatry". Lancet, 1967.

A tradução é do professor Valentim, para: "Psychiatry... is the study of abnormal behaviour from the medical standpoint: it is therefore concerned with diagnosis, prognosis, prevention and treatment". (Nota do E.) 